\title{
Correction to: $R \boldsymbol{b}$ inactivation accelerates neoplastic growth and substitutes for recurrent amplification of CIAP1, CIAP2 and Yap1 in sporadic mammary carcinoma associated with p53 deficiency
}

\section{Cheng $\cdot$ Z. Zhou $\cdot$ A. Flesken-Nikitin $\cdot$ I. A. Toshkov $\cdot$ W. Wang $\cdot$ J. Camps $\cdot$ T. Ried $\cdot$ A. Y. Nikitin}

Published online: 28 January 2021

(c) The Author(s), under exclusive licence to Springer Nature Limited 2021

Correction to: Oncogene (2010) 29:5700-5711

https://doi.org/10.1038/onc.2010.300

Following the publication of this article, the authors noted that the correct blotting image for MCF7 cells had been inadvertently misplaced during the preparation of Fig. 2A. The correct Fig. 2A is provided below. This correction does not impact any findings or conclusions in the manuscript. The authors apologise for any inconvenience caused by this error. a

a

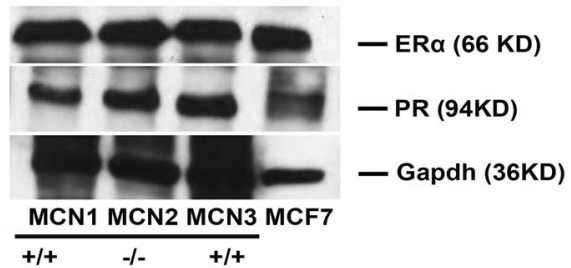

Fig. 2 